\title{
Other-Regarding Virtues and Their Place in Virtue Argumentation Theory
}

\author{
Felipe Oliveira de Sousa
}

\author{
Center for Law, Behavior and Cognition (CLBC) \\ University of Bochum \\ 44801 Bochum Universitätsstraße 150 \\ Germany \\ felipe.oliveiradesousa@rub.de
}

\begin{abstract}
In this paper, I argue that, despite the progress made in recent years, virtue argumentation theory still lacks a more systematic acknowledgment of other-regarding virtues. A fuller recognition of such virtues not only enriches the field of research of virtue argumentation theory in significant ways, but also allows for a richer and more intuitive view of the virtuous arguer. A fully virtuous arguer, it is argued, should care to develop both self-regarding and otherregarding virtues. He should be concerned both with his own development as an arguer and with helping other arguers in that regard.
\end{abstract}

Résumé: Dans cet article, je soutiens que, malgré les progrès réalisés ces dernières années, la théorie de l'argumentation de la vertu manque encore d'une reconnaissance plus systématique des vertus concernant les autres. Une reconnaissance plus complète de ces vertus enrichit non seulement le champ de recherche de la théorie de l'argumentation de la vertu de manière significative, mais permet également une vision plus riche et plus intuitive d'un argumentateur vertueux. Un argumenteur entièrement vertueux, soutient-on, devrait prendre soin de développer à la fois des vertus respectueuses de soi et des autres. Il devrait se préoccuper à la fois de son propre développement en tant qu'argumentateur et d'aider les autres argumentateurs à cet égard.

Keywords: argumentation, other-regarding virtues, virtue argumentation theory, virtuous arguers, virtue ethics

\section{Introduction}

Virtue argumentation theory is only in its beginning but has already generated some studies to explore the virtues someone needs to have to be a virtuous arguer (e.g., Cohen 2009, Aberdein 2010, 
Gascon 2018). Even though there is no consensus yet on important issues - such as whether it is possible to provide a definition of good argument in virtue-theoretical terms - it is a matter of general agreement that a reflection on the skills and virtues that are necessary for someone to be a virtuous arguer is important and should be a core part of argumentation theory (e.g., Cohen 2009, Aberdein 2010; Bowell and Kingsbury 2013; Gascon 2018). Even authors who are critical of virtue argumentation theory have acknowledged this point (e.g., Bowell and Kingsbury 2013a). ${ }^{1}$ Virtue argumentation theory is thought to be useful, among other reasons, precisely because with its focus on virtues, it highlights aspects of argumentation that, though important, have been largely overlooked in mainstream argumentation theory. It adopts a more act-based rather than an agent-based approach to argumentation, focusing on cogency, logical validity, and the like (e.g., Cohen 2008, Aberdein 2017, Gascon 2018). It has been proposed, for instance, that the focus on virtues may have profound implications for the ways in which argumentation is taught and learnt (Cohen 2008). It also broadens the field of research of argumentation theory in significant ways, for example, by calling attention to other normative criteria to assess arguments other than cogency (such as originality, creativity, fertility) and by presenting a more comprehensive and down-to-earth picture of argumentation in everyday situations (e.g., Gascon 2015, p. 480).

Even though detailed analyses of individual argumentative virtues are, to a large extent, still missing, it is generally acknowledged that virtuous arguers must display not only logical and argumentative skills such as logical consistency and accuracy ${ }^{2}$, but also certain virtues such as intellectual humility and courage, perseverance, vigor, intellectual fairness, caution, open-

\footnotetext{
${ }^{1}$ Bowell and Kingsbury claim that "there is much to be gained by identifying the virtues of the good arguer and by considering the ways in which these virtues can be developed in ourselves and in others" (2013a, p. 23).

${ }^{2}$ Other examples are: generating hypotheses, searching for evidence, considering objections, giving reasons for a claim, evaluating reasons, developing reasons into an argument, organizing an argument in a well-ordered manner, identifying fallacies, perceptual acuity (e.g. to identify irrelevant premises and distinguish a reason from a conclusion). See, e.g. Kuhn (2005, pp. 153-154).
} 
mindedness and critical insight (e.g., Cohen 2009, Aberdein 2010, Gascon 2018). ${ }^{3}$ It seems that the possession of certain virtues not only makes one a better person in general, but may also make oneself and others better arguers more specifically (e.g., openmindedness and intellectual fairness may lead to a more objective evaluation and production of arguments).

Despite the recent growth of studies in the field, there are still important gaps to be filled. In what follows, I argue that, at the current stage of its development, virtue argumentation theory (rather surprisingly in my view) still lacks a more systematic acknowledgment of other-regarding virtues. Even though there is some acknowledgment of such virtues ${ }^{4}$, this acknowledgement is far from being as full-fledged as it could and, in my view, should be. I argue below that other-regarding virtues are relevant to virtuous argumentation. They are virtues that someone aspiring to be a virtuous arguer has good reason to cultivate, nurture, and develop in him- or herself, in addition to the self-regarding ones. A fuller recognition of such virtues not only enriches the field of research of virtue argumentation theory, but also allows for a richer and more intuitive view of the virtuous arguer. To make the case for these claims, I start by introducing the distinction between selfregarding and other-regarding virtues (section 2). I then make an initial case for these claims (section 3) and present some possible reasons for why, up to the current moment, virtue argumentation theorists have given a relatively low attention to other-regarding virtues (section 4). I finally present some reasons for why promoting a fuller incorporation of other-regarding virtues into virtue argumentation theory is a good thing to do and make two suggestions as to how this could be done (section 5). In particular, I argue that certain benefits characteristic of (even peculiar to) argumenta-

\footnotetext{
3 The well-functioning of certain faculties also seems necessary, such as introspection, memory, a priori and logical intuition, inductive and deductive reasoning and the ability to draw inferences.

4 Authors who have produced lists of argumentative virtues have often identified some other-regarding virtues among them (e.g., Cohen 2005, Aberdein 2010).
} 
tion are specifically tied to, and can only be achieved by, the exercise of certain other-regarding virtues. ${ }^{5}$

Before proceeding, just a few clarificatory points. First, when I claim that there is a need for a more systematic acknowledgement of other-regarding virtues in virtue argumentation theory, I am not claiming that this is a serious failure in the theory. As I explain below, the lists of virtues provided by virtue argumentation theorists can be easily expanded to include, or give more space to, other-regarding virtues. No virtue argumentation theorist, for instance, has claimed that there is no space for other-regarding virtues in virtue argumentation theory (indeed, I wonder whether a virtue argumentation theorist would ever make such a claim). As noted above, most authors who offer lists of argumentative virtues have identified some other-regarding virtues among them. ${ }^{6}$ In my view, a fuller acknowledgment of other-regarding virtues is a natural development of virtue argumentation theory. It is just a project that has not yet been taken up or pursued in any systematic way. Even though this is the case, I do think that there are some blind-spots in virtue argumentation theory because of inattention to other-regarding virtues, and I try to remedy them in what follows. Second, when I make the above claim, I am not claiming that self-regarding virtues are irrelevant to virtue argumentation; far from this. Such virtues are clearly relevant. My claim is only that such virtues are not exhaustive, in essence, that they constitute only part of the virtues that a fully virtuous arguer would care to possess and develop. In the following (especially section 5), I argue that someone who aspires to be a fully virtuous arguer should care to develop both self-regarding and other-regarding

\footnotetext{
${ }^{5}$ I would like to thank one of the anonymous reviewers for this suggestion.

${ }^{6}$ Aberdein (2010, p. 175) mentions willingness to listen to others as a virtue. Paul (1993), to whom virtue argumentation theorists often refer, lists intellectual empathy and fair-mindedness as virtues, which are other-regarding. Other virtues that are often mentioned-e.g., open-mindedness - though not essentially other-regarding, have an important other-regarding aspect. Open-mindedness includes open-mindedness to the views and arguments of others. Cohen (2009, p. 55) stresses that it also includes "the willingness, ability, and resolve to reexamine one's own beliefs, and if called for, to let them go," which is a more self-regarding aspect of that virtue).
} 
virtues. They should be concerned both with their own development as an arguer and with helping other arguers in that regard.

\section{Self-regarding vs. other-regarding virtues}

The distinction between self-regarding and other-regarding virtues is commonplace in virtue ethics (e.g., Von Wright 1985, Slote 1995, Foot 2003). Indeed, it is one of the most often-made distinctions between the virtues. Even though it has been received in neighboring fields, such as virtue epistemology (Kawall 2002, Baehr 2011), it has not made its way yet into virtue argumentation theory. Traditionally, the distinction between self-regarding and other-regarding virtues is thought to be based on the nature of the benefit each type of virtue tends to bring about. While otherregarding virtues are primarily admired because of the contribution they tend to bring to others, self-regarding virtues are primarily admired for the benefits they tend to bring to the agent himself. ${ }^{7}$ Patience, fortitude, and perseverance are examples of selfregarding virtues. Benevolence, generosity, and justice are examples of other-regarding ones. Whereas some virtues are clearly self-regarding (e.g., fortitude, prudence), other virtues are clearly other-regarding (e.g., justice, charity, benevolence). Other virtues seem to have both an important self-regarding and an important other-regarding aspect (e.g., loyalty, honesty, trustworthiness). There are such things as being honest, loyal, or trustworthy in relation to oneself as well as in relation to others.

As some authors have argued (e.g., Slote 1995, Adams 2006), virtues of both types are worth having. They are also often interconnected. Self-regarding virtues may often help in, and even be necessary for, the exercise of other-regarding virtues and viceversa. Courage, for instance, though usually thought of as selfregarding, can be of great help for acting for the sake of others in

\footnotetext{
${ }^{7}$ Various authors explain the distinction in this way (e.g., Taylor and Wolfram 1968, p. 238, Von Wright 1985, p. 154 ff., Slote 1995, p. 91, Foot 2003, p. 2). Some authors (e.g., Driver 2003, p. 371) suggest that it can also be grasped in terms of the motivation each type of virtue characteristically involves. While other-regarding virtues characteristically involve a concern for promoting the well-being of others, self-regarding virtues primarily involve a concern for promoting one's own well-being.
} 
some situations (e.g., in situations of danger); and patience may lead the agent to be less judgmental in relation to others in such a way that others may benefit from this in the relationship they have with that agent. I therefore agree with authors, such as Hursthouse (2003), when they claim that the distinction is misconceived if it is thought that self-regarding virtues only benefit their possessor and other-regarding virtues only benefit others. In describing a virtue as (primarily) other-regarding, others are treated as the specific target of these virtues and are also the primary beneficiaries, ${ }^{8}$ which does not mean that the agent who possesses them does not benefit from them as well. Other-regarding virtues primarily involve a concern with promoting the good and well-being of other human beings, whereas self-regarding virtues do not (e.g., Taylor and Wolfram 1968, p. 244, Von Wright 1985, p. 152, Foot 2003, p. 2). Someone who exercises other-regarding virtues primarily wants to promote good consequences for others, not for themselves (e.g., Von Wright 1985, p. 152, Foot 2003, p. 2).

Admittedly, this is a rough but, in my view, adequate sketch of the distinction between self-regarding and other-regarding virtues. Even though its precise contours are a matter of some discussion, the distinction is generally acknowledged in ethical theory and seems to capture an important distinction between the virtues. In recent years, various debates happened surrounding that distinction. This distinction, for instance, has played a central role in the work of some authors (e.g., Slote 1995, 2014) to articulate a conception of the ideal ethical life as involving the cultivation of both self-regarding and other-regarding virtues. It has also allowed for reflection on related distinctions, such as that between moral virtues and other types of virtues, for example, intellectual ones (e.g., Zagzebski 1996, Driver 2003, Pouivet 2010, Baehr 2011). Some authors (e.g., Taylor and Wolfram 1968; Slote 1995) have used the distinction to call attention to the fact that contemporary ethical theories usually put a much stronger emphasis on other-regarding virtues than on self-regarding ones, thereby conferring to selfregarding virtues a lower status than they deserve. Even though

\footnotetext{
${ }^{8}$ I base this formulation on Audi's suggestion (1997, p. 212), on the "characteristic targets" of a virtue.
} 
these are interesting debates, I do not intend to take sides on them here. I am introducing the distinction mainly to give more substance to my claim about virtue argumentation theory. As I argue below, despite the progress made in recent years, virtue argumentation theory still lacks a more balanced treatment of selfregarding and other-regarding virtues.

\section{The initial case}

Even though authors who have produced lists of argumentative virtues have identified some other-regarding virtues among them, the lists they offer usually do not put a very strong focus on virtues that are other-regarding. In Cohen $(2005$, p. 64), only one of the four principal virtues present in a virtuous arguer appears to be other-regarding: willingness to listen to others. The other three virtues-willingness to engage in argumentation, willingness to modify one's position, and willingness to question the obviousare not. The first and third ones are neither other- nor selfregarding, and the second seems to be more self-regarding. ${ }^{9}$ Even willingness to listen to others, in my view, is not essentially otherregarding, since one may be willing to listen to others for nonother-regarding reasons as well (e.g., only to crash their arguments or to become more knowledgeable oneself). ${ }^{10}$ To be sure, Cohen only presents a rudimentary account of argumentative virtues. He does not even use the vocabulary of virtues to articulate it (though some of the things he says provide a clear sign that he understands

${ }^{9}$ Insofar as one is willing to modify one's position as a response to another arguer's argument, this trait may seem other-regarding. I do not think, however, that it is essentially other-regarding given that its exercise does not necessarily involve a concern for promoting other arguers' well-being.

${ }^{10}$ I am not even sure whether these traits are full-blown virtues in the traditional sense of deeply settled and stable excellences of character. As some authors have argued (e.g., Zagzebski 1996, Annas 2011), virtues in this sense are different both from natural capacities and skills. Whereas virtues are essentially related to good motivations, natural capacities and skills are not and can be used for good or bad purposes alike. Most of the traits Cohen identifies look more like natural capacities or skills than virtues in that regard. An arguer may be willing to engage in argumentation and to question the obvious with the aim of introducing other arguers to new ways of thinking, or enhancing his critical insight, or just for confusing or humiliating other arguers. 
the traits he identifies as virtues. The ideal arguer, in his view, is someone who hits the mean in the traits he identifies, that is, who displays these traits in the right degree and on the right occasions, neither in excess nor in fault. They lie, for instance, somewhere in between the concessionist arguer, who undermines their own arguments with unnecessary concessions, and the dogmatist one, who ignores questions and brushes aside objections without giving them their due; or between an excessively enthusiastic arguer, who is naïve when defending his arguments and does not consider relevant questions and objections, and a quietist one; and so on).

Aberdein's case is even more telling in that regard. Aberdein (2010) is the only author who has tried to formulate a more comprehensive list of argumentative virtues so far. Most authors usually constrain themselves to giving a few examples of relevant virtues. Aberdein uses Cohen's fragmentary account as a basic framework to develop a typology of argumentative virtues. He identifies a total of 27 virtues, among which only five seem to be other-regarding: being communicative, intellectual empathy, fairmindedness, justice, and sincerity. The vast majority of the virtues he identifies seems to be primarily self-regarding (e.g., faith in reason, intellectual courage, sensitivity to detail, intellectual candor, intellectual integrity, autonomy, perseverance, diligence, care, thoroughness). Some of the virtues he lists-for example, intellectual humility - seem to have both an important selfregarding and an important other-regarding aspect (intellectual humility may be expressed in the awareness of the fallibility of one's own arguments, as well as in the way one treats other arguers in interaction, e.g., without arrogance). Because Aberdein does not make these fine-grained distinctions in his paper, it is unclear how far he is willing to endorse them. Even though he is careful to clarify that his list is not exhaustive and that further virtues may be added, his list focuses mainly on virtues that are self-regarding and gives a lower emphasis on other-regarding ones (some very important other-regarding virtues in certain argumentative situations - e.g., generosity, gentleness - are not mentioned in his list at all).

In my view, this self-regarding focus can be viewed in other authors as well. Bailin and Battersby (2016), for instance, even 
though they mention fair-mindedness as a virtue, focus mainly on virtues such as curiosity, concern for truth and accuracy, and the desire to act on the basis of reason, which are self-regarding. And Bowell and Kingsbury (2013) stress virtues such as intellectual autonomy, epistemic humility, diligence, and courage, most of which are self-regarding. This self-regarding focus can sometimes be observed also in the critical thinking literature, to which virtue argumentation theorists often refer when identifying argumentative virtues. ${ }^{11}$ Siegel (1988), for instance, who notes the importance of certain dispositions and character-traits for good critical thinking, advances a conception of the good critical thinker that, in my view, is predominantly self-regarding. He identifies the good critical thinker primarily with a person who is disposed "to believe and act on the basis of reasons" (p. 32) and who, when "assessing claims, making judgments, evaluating procedures [...] seeks reasons on which to base her assessment, judgments and actions" (p. 33); which are more self-regarding aspects of such a person. He claims that a critical thinker "must not only be able to assess reasons properly" but must also hold "a positive self-image" and be "emotionally secure, self-confident, and capable of distinguishing between faulty beliefs and...a faulty character" (p. 41), which also indicates a focus on self-regarding traits and virtues. The same point can also be made in relation to other authors. ${ }^{12}$

When it comes to the identification of argumentative virtues, it seems to me, virtue argumentation theorists have so far adopted a

\footnotetext{
11 Though there are some notable exceptions. Ennis (1996, p. 171), for instance, includes the disposition "to care about the dignity and worth of every person" among the basic dispositions for good critical thinking. Though he does not consider this disposition constitutive of critical thinking, he claims that this disposition, as well as the sub-dispositions it presupposes (e.g., "listen to others' view and reasons"; "take into account others' feelings and level of understanding"; "avoiding intimidating or confusing others"; "be concerned about others' welfare") are all desirable traits for critical thinkers to have (see also, Paul 1993).

12 Facione and Facione (1992) focus on self-regarding dispositions such as truth-seeking, analyticity, systematicity, self-confidence, inquisitiveness, maturity of judgment and curiosity; and Perkins, Jay and Tishman (1993) stress traits such as adventurousness, intellectual carefulness, willingness to clarify and seek understanding as well as to seek and evaluate reasons, which are selfregarding.
} 
strong self-regarding focus. When other-regarding virtues are acknowledged, they are usually acknowledged in a general way and quite en passant. In recent literature, it is possible to find only some indirect references to other-regarding virtues (e.g., Thorson 2016, Stevens 2016). A fuller acknowledgment of other-regarding virtues and of the role they play in virtuous argumentation is still missing. This is a fact that demands explanation. In the next section, I explore some reasons for why this has not yet been the case. Before proceeding, let me just note that authors working in related fields usually display a much stronger acknowledgment of otherregarding virtues than virtue argumentation theorists do. Aikin and Clanton (2010), for instance, who discuss virtues for good groupdeliberation, even though they do not make an explicit distinction between self-regarding and other-regarding virtues, mention virtues of both types as relevant: deliberative wit, temperance, and courage (self-regarding), and friendliness, empathy, charity and sincerity (other-regarding). They even analyze some of these virtues in detail. Even though virtue argumentation theorists refer to their work, when they do so, they usually do so very briefly and mostly for illustrative purposes. Often, it is used an example of a related intersecting field in which a virtue-based account has been defended, without exploring the connections that might exist between it and virtue argumentation theory any further.

\section{Why has virtue argumentation theory so far displayed a low focus on other-regarding virtues?}

There might be several reasons for the relatively low attention that other-regarding virtues have received in virtue argumentation theory so far. One reason may be quite simple and is related to the novelty of the field. Virtue argumentation theory is a new field of study and, as in any field of study, there are many issues to be further investigated and questions to be clarified. How otherregarding virtues can be integrated into an account of argumentative virtues may be one of them. Because there is some acknowledgement of other-regarding virtues in virtue argumentation theory, its novelty may indeed help to explain the low attention these virtues have received. In my view, even though this might be one 
reason, upon further reflection it is also possible to find deeper, more important reasons for why other-regarding virtues have not received sufficient attention in virtue argumentation theory. Attention to these reasons is an important step to understand what one has to do, in the context of virtue argumentation theory, to promote a more systematic acknowledgment of other-regarding virtues. I turn to these reasons below.

\subsection{The analogy with virtue epistemology}

Another reason that might explain the relatively low attention to other-regarding virtues in virtue argumentation theory is the oftenmade analogy with virtue epistemology. Even though I do not deny that virtue epistemology might be a useful starting point to identify argumentative virtues, I believe it has some limitations, especially when it comes to acknowledging other-regarding virtues. $^{13}$

Virtue argumentation theorists have often taken virtue epistemology to be a useful starting point to identify argumentative virtues (Cohen 2007, Aberdein 2010, Bowell and Kingsbury 2013, Gascon 2018). Some authors go as far as suggesting that argumentative virtues are a particular type of intellectual virtues (Drehe 2015) or treat argumentative virtues as just the standard intellectual virtues identified in virtue epistemology (Johnson 2009, Battaly 2010). Even though there is some discussion as to how far drawing on virtue epistemology is a good thing to do, no virtue argumentation theorist has denied the usefulness of virtue epistemology for virtue argumentation theory. Indeed, it is in virtue epistemology that virtue argumentation theory's immediate sources lie (Aberdein and Cohen 2016, p. 339). It is generally acknowledged, for instance, that the virtues of a good epistemic agent are also virtues for the virtuous arguer (e.g., Cohen 2009, p. 3, Aberdein 2010, p. 171, Goddu 2016). ${ }^{14}$ Recently, it has been suggested that virtue

\footnotetext{
${ }^{13}$ Some authors (e.g., Aberdein 2010, Cohen 2016) note the limitations that the analogy with virtue epistemology might have to virtue argumentation theory, but no author has yet acknowledged the limitations that this analogy might have to an acknowledgment of other-regarding argumentative virtues specifically.

14 Zagzebski lists the ability to recognize salient facts; sensitivity to detail; open-mindedness in collecting and appraising evidence; intellectual humility;
} 
epistemology can serve not only as a useful source, but as the main basis or reference point for identifying the argumentative virtues. Gascon (2018) argues that, from the two varieties of virtue epistemology available - the reliabilist and the responsibilist - it is possible to derive two different (yet complementary) sets of argumentative virtues: reliabilist virtues (or skills) related to the faculties and skills necessary for an arguer to reliably produce and evaluate cogent arguments; and responsibilist virtues, the character-traits that anyone aspiring to be a virtuous arguer must also cultivate and display; for example, open-mindedness, sensitivity to detail, humility, perseverance, courage, intellectual integrity and so on.

As has been pointed out, for instance, by Kawall (2002), even though virtue ethicists have long recognized the distinction between self-regarding and other-regarding virtues, virtue epistemologists have often overlooked a similar distinction in relation to the intellectual virtues. Kawall argues that, because virtue epistemologists have been mostly concerned with what individual epistemic agents can do to maximize their own acquisition of epistemic goods (e.g., knowledge, understanding), they focus mainly on selfregarding virtues such as perceptual acuity and intellectual courage, and neglect other-regarding ones, such as generosity and integrity (p. 259). Kawall claims that this has been the case with virtue epistemologists of all stripes. In his view, other-regarding virtues are also epistemic, as much as the self-regarding ones. The only difference is that they help to produce knowledge not in the epistemic agents themselves, who possess and exercise them, but in other epistemic agents belonging to their epistemic community. They primarily aim at promoting not the epistemic agent's own intellectual well-being, as the self-regarding intellectual virtues, but the intellectual well-being of others.

While I cannot discuss Kawall's claim in more detail here, let me note that I agree with Kawall that in general (few exceptions aside; e.g., Roberts and Wood 2007), virtue epistemologists have not given a lot of attention to other-regarding intellectual virtues

intellectual perseverance; diligence, care and thoroughness as virtues (1996, p. 114). She also mentions intellectual courage, autonomy, boldness, creativity, and inventiveness as virtues. 
and have focused mainly on self-regarding ones, even though no virtue epistemologist has actually denied the existence of otherregarding intellectual virtues nor explicitly endorsed the (rather strong) claim that all intellectual virtues are self-regarding. The only author who comes close to endorsing this latter claim is Driver (2003), who maintains a strict distinction between moral and epistemic virtues (e.g., pp. 373, 374, 381). Some virtue epistemologists, however, have claimed that intellectual virtues are primarily self-regarding (Zagzebski 1996, p. 255).

The strong focus on self-regarding virtues can be observed even in virtue epistemologists who acknowledge the need to include other-regarding virtues in an account of intellectual virtues. Baehr, for instance, explicitly rejects the view that intellectual virtues are exclusively self-regarding (2011, pp. 110-111). He stresses that intellectual virtues need not aim solely "at one's own acquisition of truth, knowledge, or similar epistemic goods," but can also be aimed "at the epistemic flourishing of others." He claims not only that certain intellectual virtues are essentially other-regarding (e.g., intellectual generosity), but also that all intellectual virtues have an other-regarding aspect since they can all "be oriented toward, or put in the service of, another person's share in the epistemic goods" (p. 217). ${ }^{15}$ Even though this is the case, Baehr still gives a more prominent focus to self-regarding virtues than to otherregarding ones. In his six "natural groupings" of intellectual virtues, Baehr only mentions virtues that are self-regarding (e.g., inquisitiveness, reflectiveness, contemplativeness, curiosity, sensitivity to detail, intellectual flexibility). The only other-regarding virtue to which he devotes some attention in the book is intellectual generosity (and still, he analyzes this virtue in only two pages). To be fair, Baehr acknowledges that his six natural groupings of intellectual virtues do not offer "a strict classification or taxonomy" of intellectual virtues. As he explains, they are only meant to shed light on some ways in which certain traits "are useful for overcoming [...] familiar obstacles to successful [personal] inquiry" (p. 17). Still, he takes the basis of his taxonomy to be the

\footnotetext{
${ }^{15}$ In his view, this is the case even with virtues that seem to be exclusively selfregarding, such as curiosity.
} 
role that intellectual virtues play in the context of personal inquiry and focus mainly on virtues that are self-regarding. ${ }^{16}$ This selfregarding focus can also be viewed in the way Baehr defines the intellectually virtuous person, as "one who thinks, reasons, judges, interprets, evaluates, and so on, in an intellectually appropriate or rational way" (p. 18) or who has "a positive psychological orientation toward [...] epistemic goods like knowledge and understanding" (p. 14). This emphasizes the self-regarding aspects of such a person.

In my view, the only notable exception in virtue epistemology when it comes to acknowledging other-regarding virtues is the work of Roberts and Wood (2007). Roberts and Wood stress, in several passages, that intellectual virtues include both virtues that help in the acquisition of intellectual goods as well as in their transmission (p. 35; 61; 73; 79; 144; 164). Differently from other virtue epistemologists (who are usually silent in that regard), they clarify from the start that intellectual virtues "foster the delivery of the epistemic goods in general, not just [...] their possessor's acquisition of them" (p. 144). They claim, for instance, that anyone who loves knowledge in a mature (i.e. virtuous) way "will inevitably have some skills for acquiring knowledge [for oneself] and passing it on to others" (p. 73) and that "love of knowledge is not just a love of epistemic goods as such, but [also] of other people's having them" (p. 165) in such a way that an otherregarding motivation is essentially involved. They also analyze some other-regarding intellectual virtues in detail-for example, generosity, gentleness, intellectual charity, and truthfulness.

Most virtue epistemologists, however, still put their emphasis mainly on self-regarding virtues. They identify the good epistemic agent primarily with someone who is good at acquiring knowledge and other intellectual goods for herself, rather than with someone who is also good at helping others in that regard. Insofar as this is the case, they end up relying on an account of intellectual virtues that puts a stronger focus on self-regarding virtues than on otherregarding ones.

\footnotetext{
${ }^{16}$ In my view, if Baehr had not restricted himself to the context of individual intellectual inquiry, his taxonomy could easily be expanded to include otherregarding virtues.
} 
If one takes this fact into account, it is possible to see why the analogy with virtue epistemology may indeed be a reason for the relative lack of attention to other-regarding virtues in virtue argumentation theory. If what I claimed above is true, and virtue epistemology has focused mainly on self-regarding virtues, it is not surprising that, if to obtain a list of argumentative virtues one draws an analogy with virtue epistemology, the resulting list will tend to focus on self-regarding virtues. The strategy recently adopted, for instance, by Gascon (2018), whereby the two varieties of virtue epistemology are combined to obtain an account of argumentative virtues, will not solve this problem. Such an account, even though it would be richer than the account one would obtain if one only relied on either one or the other approach of virtue epistemology, would still not give a very prominent space to otherregarding virtues and would focus primarily on self-regarding ones. Even though, as I note below (section 5), what some authors have claimed in relation to the virtuous arguer is a clear indication that, in their view, the virtuous arguer should possess both selfregarding and other-regarding virtues, their focus is still mainly on virtues that are self-regarding. Aberdein (2010), for instance, when formulating his list of argumentative virtues, still draws too closely on the list of epistemic virtues offered by virtue epistemologists, especially Zagzebski (1996), who, as I mentioned above, explicitly claim that epistemic virtues are mainly self-regarding. ${ }^{17}$

\subsection{The focus on justification as a goal of argumentation}

In my view, another reason for the low attention to other-regarding virtues in virtue argumentation theory might be the centrality of justification as a goal of argumentation. Argumentation theorists have for long recognized justification as a central goal of argumentation (e.g., van Eemeren and Grootendorst 1984, Toulmin 2002 , p. 2, Bermejo-Luque 2011, Govier 2013, p. 1). Virtue argumentation theorists have sometimes also acknowledged this point

${ }^{17}$ Even though, like Aberdein, Cohen (2016) acknowledges the limits of the analogy with virtue epistemology for virtue argumentation theory, he insists that virtue argumentation theory should take its cue from virtue epistemology (especially from the responsibilist side, which, as just explained, has a selfregarding focus). 
(e.g., Cohen 2005, p. 1, Bowell and Kingsbury 2013, p. 23, Gascon 2015, p. 468, Bailin 2018, p. 23). Cohen (2005, p. 1), for instance, even though he notes that justification is not the only nor the "essential or defining goal" of argumentation, claims that a lot "of what argumentation is about is the process whereby reasons are offered to bring that end about," in essence, to "raise the credibility of the target conclusion." Good arguments in a justificatory sense are certainly something we expect virtuous arguers not only to be able to produce, but also to produce often, and to be motivated to produce. Most authors, when they characterize the virtuous arguer, claim that the virtuous arguer must be someone who systematically produces good arguments in a justificatory sense ${ }^{18}$ (Goddu [2016, p. 4], for instance, claims that "a virtuous arguer never knowingly puts forward fallacious arguments" and "knows that the premises [he puts forward are true and] sufficiently support the conclusion"; Aberdein [2017, p. 4], argues that "a virtuous arguer can put forward a bad argument, but not qua a virtuous arguer...[i.e. if he argues as] a virtuous arguer would argue"; and Gascon [2018, p. 163], claims that "the virtuous arguer is someone who reliably produces good arguments").

Given the centrality of justification as a goal of argumentation, it may be tempting to think that the virtues and skills of the virtuous arguer are just the virtues and skills present in someone who is good at achieving justification, in essence, who is good at producing good arguments in a justificatory sense. One may think, for instance, that as much as a character-trait gets to be on the list of epistemic virtues because it promotes an alignment of belief and truth, ${ }^{19}$ a character-trait gets to be on the list of argumentative virtues if its possession promotes an alignment to justification, that is, if it increases the chances of the reliable production and appreciation of good arguments in a justificatory sense. As much as epistemic virtues are viewed as derivatives from the motivation of achieving knowledge and correlated states (such as understanding,

18 By a "good argument in a justificatory sense," I mean an argument that provides, via its premises, sufficient justification for believing its conclusion to be true or probable.

${ }^{19}$ Virtue epistemologists have often adopted this line of reasoning (e.g., Zagzebski 1996, p. 166, Goldman 2003, p. 31). 
truth, wisdom), argumentative virtues are viewed as derivatives from the motivation of achieving justification. In this way of thinking, the motivation of achieving justification is primary and the virtues and skills of the virtuous arguer are identified in terms of it, not the other way around. The virtuous arguer is then primarily viewed as someone who is motivated to produce and appreciate good arguments in a justificatory sense.

It is unclear to me whether virtue argumentation theorists would endorse such a justification-based account of argumentative virtues. Informal logical approaches clearly encourage such an account. ${ }^{20}$ Virtue argumentation theorists are often not very explicit when it comes to explaining the criteria they use to identify argumentative virtues. Usually, they only note some similarities between virtue argumentation theory and other fields in which virtue-based approaches have also been defended (such as virtue epistemology) and claim that the virtues identified in those fields are also possible candidates for argumentative virtues. At best, there are only some hints in the work of some virtue argumentation theorists-especially in the way they sometimes characterize the virtuous arguer - that they might be inclined to endorse such an account (the situation, in my view, is different in the case of argumentation theorists more generally, some of whom do take justification to be the central goal of argumentation ${ }^{21}$ ).

Even though evidence is inconclusive here, the focus on justification may yet be another reason for the low attention to otherregarding virtues. To elaborate this point, let me reflect a bit further on the conception of the virtuous arguer that underlies the focus on justification, that is, that someone who poses justification as the central goal of argumentation would be committed to. In such a conception, the virtues that someone aspiring to be a virtuous arguer would need to cultivate in him- or herself are mainly self-regarding. The virtuous arguer would need to be selfconfident, courageous, determined, perseverant, thorough, cautious in the pursuit of his own arguments. He would also need to be intellectually humble and embrace only claims that are warrant-

\footnotetext{
20 This point has been acknowledged, e.g., by Gascon (2015, pp. 467-468).

${ }^{21}$ See footnote 39 for references.
} 
ed in light of the reasons he is prepared to give as well as being intellectually canny, for example, quick in spotting missing connections in his arguments as well as in making them. These are only a few examples of the virtues a virtuous arguer would exhibit in such a conception. There are many others, for example, patience, intellectual autonomy, intellectual honesty, integrity. In contrast to some authors (e.g., Gascon 2015), I think that a justification-based conception is well placed to capture a significant part of the virtues that a virtuous arguer is expected to have and develop. Most responsibilist virtues, for instance, would fit well in this conception (e.g., perseverance, courage, attention to detail, intellectual carefulness, to mention just a few examples). If one reflects more closely on the nature of these virtues, it is not hard to see why. An arguer who is careful, thorough in evaluating evidence, patient, perseverant, attentive to detail, etc. is more likely to reliably produce good arguments in a justificatory sense than an arguer who is not. Even though the possession of these virtues does not guarantee the production of good arguments in a justificatory sense - a given arguer may lack these virtues and still produce on occasion good arguments in a justificatory sense (e.g., Cohen 2013, Bowell and Kingsbury 2013a, p. 30, Gascon 2015, p. 482)an arguer who exhibits such virtues is more likely to produce good arguments in a justificatory sense than an arguer who lacks them. He would be, for instance, less prone to commit argumentative mistakes, such as jumping to conclusions, ignoring relevant facts or details, lacking critical insight or analytical depth, than an arguer who does not possess them.

This point, in my view, could have been better appreciated in virtue argumentation theory if a distinction were made, similar to the one made in virtue epistemology (e.g., Zagzebski 1996, pp. 273-283, Roberts and Wood 2007, p. 8), between low-grade and high-grade arguments. While it does not take a lot of virtue for the production and appreciation of low-grade arguments - to produce and appreciate simple logical syllogisms only basic logical skills are necessary - to fully appreciate the depth and insight of certain 
arguments, virtues such as patience, humility, and perseverance are clearly helpful. ${ }^{22}$

The problem that I see in a justification-based conception, thus, is not that it would be a poor conception of argumentative virtues, but that it is likely to be incomplete. Such a conception is well placed to capture only part of the virtues that a fully virtuous arguer should care to possess and develop. Important as they are, the virtues identified are all self-regarding. Even though their exercise may have positive consequences for other arguers - for example, other arguers may be in a better position to understand the argument being proposed, or enhance their understanding about the arguer's own position or even about their own in comparison-their possession primarily helps the arguer to improve the quality of his own arguments rather than those of other arguers. An arguer who is motivated to achieve justification is primarily moved by self-regarding concerns. He does not necessarily exhibit any other-regarding concerns. Indeed, he may even exhibit no other-regarding concerns at all. He may be systematic, careful, courageous, thorough, rigorous, intellectually sharp, etc. in his own argumentative endeavors and still be an argumentative jerk, for example, he may be arrogant and cold-hearted toward other arguers, view them as inferior, not wish them well, and so on (similar claims are made in virtue epistemology, e.g., Pouivet 2010, Baehr 2011, pp. 206-210). He may even desire not to help other arguers at all. Even though this is not a necessary feature of the virtuous arguer-a virtuous arguer may be motivated to achieve justification and also have other-regarding concernsother-regarding concerns are not a necessary or at least not a very prominent set of concerns for the virtuous arguer in such a conception.

The underlying reason for this is easy to flesh out: justification, just like knowledge in that regard, is primarily a self-regarding good. ${ }^{23}$ Even though the search for it can benefit from the coopera-

\footnotetext{
${ }^{22}$ I therefore disagree, e.g., with Gascon $(2018$, p. 167) when he claims that the relation between responsibilist virtues and the justificatory quality of arguments "is at best weak."

${ }^{23}$ For a similar claim in the context of virtue epistemology, see Zagzebski (1996, pp. 255-256).
} 
tion of other arguers (indeed, it is possible that the search for justification is at its best with the help of other arguers, critical arguers, that provide one with intellectual challenges and the appropriate encouragement to improve. See, e.g., Mercier and Sperber 2017 , pp. 218-221), the primary aim of the motivation to achieve justification is a self-regarding one. Namely, it is to build and produce something for oneself: good arguments in a justificatory sense. Insofar as this is the case, the focus on justification is likely to lead to a stronger focus on self-regarding virtues than on other-regarding ones.

It is possible, indeed likely, that the virtuous arguer in such a conception will appreciate engaging in a live debate with other arguers to test his arguments. He is aware, for instance, that in the process of expressing his arguments to other arguers, he may become aware of overlooked flaws in them or of under-developed steps that need further refinement; or even that he may discover more fully what the argument he initially envisaged 'in his head' actually is. ${ }^{24}$ Because he is concerned with becoming a better arguer himself, he will, in general, value contact with arguers who help him grow as an arguer. Note, however, that even though he is open to engage with other arguers in the ways just described, he does so primarily for self-regarding reasons. Essentially, he does so for the contribution that other arguers may make to him by way of improving his arguments rather than for other-regarding reasons; that is, for the contribution that he can himself make to other arguers in that regard. If argumentation is viewed primarily as a tool for achieving justification, one will end up focusing mainly on self-regarding virtues, given that these are the virtues whose cultivation enhance the arguer's capacity to defend his arguments against challenges, to propose well-developed arguments, and the like. Because of this self-regarding orientation, even the exercise of other-regarding virtues might acquire a strong self-regarding focus. Take, for instance, intellectual charity, which is a virtue that the virtuous arguer will probably exhibit in such account, especially when engaging with the arguments of other arguers. For such an

\footnotetext{
${ }^{24}$ This feature has been stressed, for instance, by Charles Taylor $(2015$, p. 257 ff.), who claims that in the act of formulating or making an idea explicit, we often come to have a more articulated view of it.
} 
arguer, intellectual charity may be valuable less because of the respect he expresses to other arguers and their arguments (or not primarily for this reason), and more because its exercise may enhance the merits of the argument he proposes in some way (e.g., it may increase its respectability or academic quality) - that is, primarily for self-regarding reasons. His primary aim here still is to make his own arguments stronger, rather than to strengthen or develop the arguments of other arguers, say, for their own sake.

\section{Towards a more systematic acknowledgment of other- regarding virtues}

\subsection{Defining the virtuous arguer with other-regarding virtues}

There are several benefits that a fuller acknowledgment of otherregarding virtues might bring to virtue argumentation theory. One central benefit, in my view, is that such acknowledgment would lead to a more intuitive and richer conception of who a fully virtuous arguer is. The best arguers, in my view, possess and care to develop both self-regarding and other-regarding virtues. They care both about their own development as arguers and about helping other arguers in that regard. Think, for instance, of an arguer who, because he cares about other arguers' well-being and wants them to excel, spends considerable time and effort helping them improve their arguments, regularly engaging in discussions to clarify any questions they might have. They are keen to spot confusions in their thoughts, make them aware of their weaknesses, give appropriate encouragement to them when needed, suggest ways to improve, check in on a regular basis to make sure they understood a certain point, and so on. They are even willing to sacrifice some of their own goals as an arguer (e.g., improving a paper for publication) to stay a bit longer with them. ${ }^{25}$ It is entirely reasonable to think that such an arguer is being an excellent arguer, even if they are not concentrating on improving their own argumentative self. In this case, they are using their well-developed capacities as an arguer primarily to help other arguers improve their own. In my

25 Similar cases are discussed in virtue epistemology (e.g., Kawall 2002, Baehr 2011, p. 111). 
view, this is no small aim. It takes exceptional arguers to do this well (Socrates' example comes to mind here ${ }^{26}$ ). A fuller acknowledgement of other-regarding virtues would allow us to see such arguers - who help other arguers grow as arguers - as excellent arguers as well.

Note that such arguers will exhibit a host of other-regarding virtues in addition to the self-regarding ones, for example, friendliness, the disposition to enjoy interaction with other arguers and entertain friendly discussions with them; gentleness, the disposition to express oneself mildly while nevertheless speaking what one takes to be the truth about the arguments of fellow arguers; generosity, the disposition to invest one's time, effort, attention, experience to help other arguers freely, gladly, and for those arguers' own sake ${ }^{27}$; respectful criticism, the disposition to criticize the arguments of other arguers in a respectful and constructive manner, without mocking or ridiculing them; and so on. Even though such virtues primarily aim at promoting the well-being of other arguers, they may constitute an important part of the flourishing and well-being of the arguer who exercises them. Due to the help he gives to other arguers, for instance, he may experience the rewards of friendship, gain the respect of other arguers, more qualified partners for interaction, even improve his own argumentative skills. He may even acquire or further develop certain virtues (e.g., open-mindedness, humility). The value of otherregarding virtues, thus, is not exhausted by their instrumental value in enhancing other arguers' well-being. They may also generate important self-regarding gains (though, of course, the benefits they bring to other arguers constitute an important part of their value). ${ }^{28}$

${ }^{26}$ Vlastos (1991, p. 32) claims that Socrates engaged in argumentation with fellow arguers "to make them aware of their own ignorance and enable them to discover [the truth] for themselves," with the ultimate aim to assist them in "their own effort at moral self-improvement" (all of which are other-regarding aims).

${ }^{27}$ For an analysis of generosity, see Roberts and Wood (2007, chap. 11).

${ }^{28}$ In my view, these virtues do not have to actually benefit other arguers in order to be valuable. As some authors have argued (e.g., Blum 1980, p. 140 ff.), exercising other-regarding virtues is admirable partly in itself, simply in virtue of the concern one expresses to others and their well-being. 
In my view, fully virtuous arguers not only desire to become better arguer themselves, but also desire that fellow arguers become better arguers and are willing to make contribution to them in that regard. A fully virtuous arguer cares about the well-being of fellow arguers for their own sake. ${ }^{29}$ Becoming a better arguer, for them, also involves improving their behavior in relation to other arguers, for example, they may ask: should I become more patient with fellow arguers? Am I devoting sufficient time and effort to help them develop their arguments? Am I sufficiently precise when I criticize their arguments and open to their ways of thinking? These are all questions that a fully virtuous arguer would also have. They would not be, so to speak, a selfish arguer whose sole concern is to improve the quality of their own arguments. Even though they are concerned with that as well, they also desire to help other arguers improve their own. Instead of being someone who is willing to give up most of their goals as an arguer in an effort to help other arguers or to entirely neglect helping other arguers to favor his own goals, a fully virtuous arguer tries to reach a balance between these two aims. They are neither only self-regarding nor only other-regarding. They are both. ${ }^{30}$ They understand that in some situations, it is more important to be selfregarding, whereas in other situations, it is more important to be other-regarding. They also know that unless they take proper care of themselves (through the cultivation of the self-regarding virtues, e.g., if they keep themselves in good shape, mentally healthy, and so on), they will not be in a good position to help other arguers.

This conception of the virtuous arguer not only fits well with ordinary intuitions but is also more plausible than a conception that focuses mainly on self-regarding virtues. This conception has an important parallel with the conception of the good epistemic agent that some authors have defended in the context of virtue

\footnotetext{
29 This addition is important. If his reason for helping fellow arguers were broadly egoistic (having to do with the benefits that helping other arguers may bring to himself), he would not be a fully virtuous arguer in the conception I am defending. He would still be taking primarily his own good, rather than the good of other arguers, into account. Some authors have made this claim in virtue ethics (Annas 2008, p. 208, Kraut 2016).

${ }^{30}$ For a similar point in relation to ethical agents, see Slote $(2014$, p. 74$)$.
} 
epistemology (most notably, Kawall 2002, but also, Baehr 2011) as well as of the ideal ethical agent that some authors have defended in the context of virtue ethics (e.g., Slote 2014). It also helps to expand some insights present in virtue argumentation theory that remain under-explored. Aberdein (2010), for instance, when he characterizes the virtuous arguer, claims that differently both from a good epistemic agent (who, according to him, is primarily assessed in terms of their "self-directed qualities") and from a good ethical agent (who, according to him, is mainly assessed in terms of their "other-directed qualities"), the virtuous arguer is assessed in terms of both (p. 176). He claims that, apart from the selfdirected aspect that a good arguer also has - a good arguer, he claims, is "also concerned with the success of his own arguments" (p. 176) - there is also an other-directed aspect to the good arguer that is not necessarily (or at least not so prominently) present in a good epistemic agent. Unfortunately, Aberdein does not explore any further what these other-directed qualities of the virtuous arguer might be. In my view, this is a valuable but under-explored insight that the conception of the virtuous arguer articulated above-which views the virtuous arguer as having both selfregarding and other-regarding concerns - helps to put into clearer focus.

Certain arguers would readily count as not fully virtuous under this conception. An arguer who desires to help fellow arguers but systematically fails to help them (because, say, he is intellectually naïve and is unable to give good feedback to them) is not a fully virtuous arguer. But neither is fully virtuous an arguer who is able to make sharp comments to fellow arguers, but does so in a way that may be perceived as vicious (e.g., in the attempt to humiliate or intimidate them).$^{31}$ Nothing in my conception, of course, denies that such arguers may help other arguers grow as arguers. (Indeed,

\footnotetext{
${ }^{31}$ Norlock (2014, p. 2) discusses the case of an arguer who listens to other arguers only to criticize them into the ground, keenly watching for opportunities to identify weaknesses in their arguments and to capitalize on them. In the conception I am defending, such an arguer, however sharp he might be, is not a fully virtuous arguer, given his lack of other-regarding orientation and concern for other arguers' well-being.
} 
there might be a lot to learn from interaction with such arguers, including in relation to what not to do. That will largely depend on the ability of other arguers to distinguish the content of the criticism raised from the way in which it was made, which may, in turn, depend on how much of certain self-regarding virtues they have, e.g., self-confidence, perseverance). Even though this is the case, such arguers are not fully virtuous in the conception I am defending. In this conception, an arguer is fully virtuous only if they relate to other arguers in morally virtuous ways. Whatever they do here, they must do it primarily for other arguers' own sake, out of a genuine concern for their well-being and a desire to promote good consequences for them. ${ }^{32}$

\subsection{Further benefits of a fuller acknowledgment of other-regarding virtues}

A fuller acknowledgment of other-regarding virtues also has the advantage of better placing virtue argumentation theory to cover the wide-range of argumentative situations that are available in everyday life. In argumentative situations whose central aim is education, for instance, other-regarding virtues are likely to have an important role to play. These are situations in which the primary aim is to nurture in other arguers (e.g., younger ones) the virtues and skills that are necessary for them to excel as arguers. Teachers, interlocutors, thesis supervisors are all in the business of helping other arguers improve as arguers. Success in such roles require a host of other-regarding virtues in addition to self-regarding ones. This is different in other types of situations. In the defence of a $\mathrm{PhD}$ thesis, for instance, where the central aim is to test the quality of the arguer's argument (the $\mathrm{PhD}$ candidate) as well as their capacity to defend it, the arguer will be expected to display an

\footnotetext{
${ }^{32}$ Another way of putting the point is to say that, in these cases, there is a sense in which such arguers are being excellent arguers (given their ability to make sharp criticisms, identify weaknesses in the arguments of fellow arguers, etc.), but are unethical. The conception I advance proposes to include the ethical aspect in the very definition of the (fully) virtuous arguer. In this conception, an arguer who displays an active concern for helping other arguers is pictured in a more favourable light than an arguer who does not. I would like to thank Karolina Prochownik for pushing me to clarify this point.
} 
array of self-regarding virtues, for example, self-confidence, determination, firmness, perseverance, and so on (though the possession of some other-regarding virtues, such as charity to the criticism raised by the examiners, may also help). A fuller acknowledgment of other-regarding argumentative virtues side-by-side with the self-regarding ones enriches the field of study of virtue argumentation theory in significant ways. As a rule, when argumentation is performed for certain purposes (e.g., education, critical discussion), other-regarding virtues are likely to have a relevant role to play as much as the self-regarding ones. ${ }^{33}$

If one views argumentation as a social practice (e.g., Rooney 2012 , p. 319), one that involves participation in a variety of more specific activities - such as presenting arguments to other arguers, responding to the arguments of other arguers, modifying one's arguments in light of other arguers' responses, helping other arguers develop their arguments further, and so on-other-regarding virtues come naturally into the picture. Successful engagement in many of these activities seems to require the exercise of otherregarding virtues, as much as of self-regarding ones. Arguers involved in such activities are involved in a network of relationships that are by-and-large sustained by processes of argumentation. It is unlikely that these relationships can be kept in good shape without the exercise of certain other-regarding virtues, for example, respect for other arguers, generosity, truthfulness, and so on. Insofar as these relationships are conducive to the formation of argumentative communities, the exercise of other-regarding virtues also seems necessary for these communities to flourish. This point has been sometimes raised in virtue epistemology (e.g., Code 1987, p. 192, Kawall 2002, p. 260, Roberts and Wood 2007, p. $114 \mathrm{ff}$.$) .$

\footnotetext{
${ }^{33}$ The presence of other-regarding virtues is less strong in situations that have a more self-regarding focus, such as negotiation, in which arguers participate with the aim of getting the best deal for themselves in a conflict of interests; or eristic discussions, in which their main goal is to win the argument (e.g., Walton and Krabbe 1985, p. 65 ff.). Even in these situations, other-regarding virtues may have a role to play. Arguably, arguers who take the interests of other arguers into account have a better chance to arrive at a deal in a negotiation than arguers who do not.
} 
With a fuller acknowledgment of other-regarding virtues, it also becomes possible to see the interesting relationships that might exist between both types of virtues that are worth further exploring. For instance, one way of teaching other arguers the relevant self-regarding virtues is by behaving oneself in the way these virtues require, essentially, in a careful, precise, patient, perseverant, etc. manner in argumentative interactions with them. By setting the example oneself, one may succeed in making other arguers acknowledge the importance of such virtues for good argumentative interaction and also in inspiring them to cultivate such virtues in themselves (the same goes for other-regarding virtues). ${ }^{34}$

Other-regarding virtues may also be an important device against certain biases. Arguers who are attentive and open-minded to what other arguers think about their arguments, for instance, are likely to be better in overcoming overconfidence regarding their own arguments than arguers who are not. As has been argued, for example by Mercier and Sperber (2017, p. 213), arguers who reason proactively in the attempt to defend their arguments are likely to develop a confirmation bias, that is, a tendency in favor of confirming their own arguments, which is usually coupled with a bias in favor of disconfirming opposing claims and counterarguments. This bias seems most likely to generate bad results in situations of lonely thinking, when arguers produce arguments without receiving input from other arguers, in such a way that the best way of mitigating it is through interaction with other arguers, especially with arguers who favor points of view different from one's own. The cultivation of certain other-regarding virtues (e.g., fair-mindedness, attentive listening) seems to be necessary for these interactions to work well. An arguer who interacts with other arguers but is not open to what they have to say or is not disposed to take their criticisms seriously into account is less likely to benefit from the input received than an arguer who exhibits these virtues. It may well be that, as Mercier and Sperber suggest, arguers can develop only a limited ability to overcome this bias (given that it is a natural pre-disposition that all arguers exhibit in some de-

\footnotetext{
${ }^{34}$ On the importance of exemplars for learning the virtues, see, e.g., Battaly 2015, Zagzebski 2017.
} 
gree), in which case the role of other-regarding virtues would be not to fully eliminate it, but to reduce its effects as much as possible. Other-regarding virtues seem particularly relevant to mitigate biases deriving from what Johnson and Blair (2006, p. 191) call "egocentric commitments," in essence, the set of personal interests and attachments that distort the way we treat information and the way we argue. They mention "a failure to recognize another point of view, to see the possibility of an objection to one's point of view, or to look at an issue from someone else's point of view" ( $p$. 193) as examples.

A last but no less important reason for a fuller acknowledgment of other-regarding virtues lies on the level of social critique. As several authors point out, our current culture privileges adversarial argumentative interactions to more cooperative ones (e.g., Moulton 1983, Tannen 1998, Rooney 2010). Tannen, for instance, one of the most well-known proponents of this view, claims that our current culture is "corroded by [...] an atmosphere of unrelenting contention - an argument culture," as she calls it, that makes us approach the world and people in it by-and-large in an adversarial frame of mind (1998, p. 3). Tannen argues that, in this culture, arguers are socialized to be aggressive and confrontational, rather than cooperative and helpful. They are encouraged to view each other as opponents, to defend their arguments and shield them against criticism, to attack the arguments of other arguers and look for weaknesses in them, and so on. ${ }^{35}$

This paper, of course, is not the right place to assess whether the diagnosis that Tannen makes (among others) of our current argument culture is correct. No doubt there is plenty of evidence in current state of affairs that could be adduced in its favor. (In her book, Tannen presents plenty of evidence to demonstrate how pervasive this aggressive style of argumentation is in our current culture, for example, in the media, politics, academic discussions. In her view, this style is deeply rooted in the dominant, male-

\footnotetext{
${ }^{35}$ Lakoff and Johnson also claim that "the ARGUMENT IS WAR metaphor is one that we live by in this culture." They claim that we "don't just talk about arguments in terms of war... [but] can actually win or lose arguments... see the person we are arguing with as an opponent... attack his positions and...defend our own" (1980, p. 4).
} 
oriented perspective that positively values aggressive behavior in argumentation and conflates aggression with success. ${ }^{36}$ See also Moulton 1983). If this diagnosis is at least partially correct, it follows that our current culture favors much more the development of self-regarding argumentative virtues than of other-regarding ones. Self-regarding virtues such as determination, courage, firmness, perseverance in the face of strong criticism are the virtues arguers need to cultivate in order to succeed in a culture that puts a stronger emphasis on confrontational and aggressive modes of argumentation than on more cooperative ones. Furthering a closer reflection on other-regarding argumentative virtues may thus help to redress the balance and also to bring virtue argumentation theory closer to social concerns. Arguably, other-regarding virtues are the virtues whose cultivation is necessary to counter the aggressiveness that is pervasive in our current argument culture. Tannen suggests as much when she claims - even though she does not put the point in the language of virtues - that the move from adversarial interactions to more cooperative ones is only possible if people move beyond a dualistic way of thinking (open-mindedness; empathy), carefully listen to the other side, and treat others well (hospitality), all of which are other-regarding virtues or at least virtues that have an important other-regarding aspect, such as open-mindedness.

\subsection{Two steps for a fuller acknowledgment of other-regarding virtues}

In my view, there are two interconnected steps that should be taken for promoting a more systematic acknowledgment of otherregarding virtues in virtue argumentation theory. The first step is the endorsement of a truly pluralistic account of argumentative goods, that is, of the goods that can be achieved through argumen-

\footnotetext{
${ }^{36}$ Tannen adds that this style is also deeply ingrained in Western philosophical tradition, which is largely based-since the Greeks - on confrontational and antagonistic modes of argumentation, rather than on more cooperative ones.
} 
tation. Such an account must include not only self-regarding goods such as justification, deeper understanding, and appreciation of arguments, but also other-regarding ones, such as helping other arguers grow as arguers, making them sharper arguers, and so on. The second step is a more explicit acknowledgment of the variety of roles arguers can occupy in argumentative situations. As I argue below, whereas some roles are strongly self-regarding and require the exercise of a manifold of self-regarding virtues, other roles are strongly other-regarding and require the exercise of a host of other-regarding ones. Once these two steps are taken, otherregarding virtues such as generosity, gentleness, attentiveness would have a place in virtue argumentation theory as much as the self-regarding ones. The first step is less common in current accounts than the second one. Whereas an explicit endorsement of good-pluralism is not often found in virtue argumentation theory, ${ }^{37}$ some authors do acknowledge role-relativity as an important factor to identify argumentative virtues, even though they have not acknowledged its relevance to a fuller acknowledgment of otherregarding argumentative virtues more specifically (Cohen 2013, Bowell and Kingsbury 2013, Stevens 2016).

A truly pluralistic account of argumentative goods acknowledges from the start that there are a variety of important goods that can be pursued by argumentation. Among them, there is not only a range of self-regarding goods, such as deeper understanding and appreciation, self-knowledge, and critical insight, but also otherregarding ones, such as helping other arguers become better arguers, more precise in their arguments, enhance their self-knowledge, and so on. ${ }^{38} \mathrm{~A}$ truly pluralistic account of argumentative goods stresses that, even though many of these goods have not attracted the attention they deserve in mainstream argumentation theory, ${ }^{39}$

37 Cohen $(2007,2009)$ is the only author who provides a more articulated defence of this view. Good-pluralism is more often endorsed in virtue epistemology (e.g., Roberts and Wood 2007, pp. 36-39).

${ }^{38}$ For an analysis of how argumentation can be used for therapeutic purposes to promote emotional growth and release, see Nussbaum (1996).

${ }_{39}$ Mainstream argumentation theory has given prominent attention to three goods: justification, rational persuasion, and resolution of conflict. Argumentation theorists usually consider one of these three goods to be the most fundamental good of argumentation. Toulmin suggests that justification is "the 
they are all important goods that can be pursued by argumentation and that arguers have good reason to facilitate and foster them both in themselves and in fellow arguers.

That there are a variety of goods that can be pursued by argumentation is a fact largely acknowledged in mainstream argumentation theory (e.g., Walton and Krabbe 1985, p. 66, Gilbert 1997, p. 67 , Johnson 2000 , p. 12). It has not, however, made its way yet into virtue argumentation theory. In fact, Cohen seems to be the only author in the field who provides a more articulated defense of pluralism in relation to argumentative goods (2007, 2009). Most authors only briefly hint at it. In several of his writings, Cohen claims that there are more cognitive achievements that can be reached through argumentation than the ones often emphasized in argumentation theory, namely, justification, rational persuasion, and resolution of conflict (e.g., 2007, pp. 5-6, 2009, p. 5). Other cognitive achievements include, in his view, a deepened understanding of one's position; the improvement of one's position; the abandonment of a standpoint for a better one; a deepened understanding of an opponent's position; greater acknowledgment of (the reasonableness) of another's position; greater attention to previously over-looked or under-valued details; and a better grasp of connections and of how things might fit together in a big picture. Cohen claims that, even though these are not among the most common cognitive changes that may occur in the course of argumentation (according to him, the most common changes are "the moves from disbelief or non-belief to belief, and the reverse" [2008, p. 7]), they are all important cognitive changes that can be achieved by argumentation. Some of them, he claims, can even have deep, long-lasting effects in an arguer and lead them to reevaluate their arguments and points of view more deeply. Cohen

primary function of arguments" (2002, p. 12); Bermejo-Luque adopts a similar view when she claims that justification is the "constitutive goal" of argumentation (2011, p. 36 ff.). For a similar claim in relation to rational persuasion, see, e.g., Johnson (2000, p. 159). Van Eemeren and Grootendorst (1984, p. 18) seem to adopt a mixed view when they define argumentation as "a speech act [...] designed to justify or refute an expressed opinion and $[. .$.$] to convince a ration-$ al judge $[. .$.$] in respect of the acceptability or unacceptability of that expressed$ opinion." 
notes, more generally, that there are various short-term and longterm, positive and negative, effects that may result from argumentation. Argumentation may upset and discourage arguers, but it may also energize and stimulate them to re-evaluate or re-think their arguments and so on.

What Cohen says, in my view, is a clear indication that he endorses a pluralistic account of argumentative goods. He clearly supports an expansion of traditional lists of argumentative goods in order to include other important goods that can also be achieved through argumentation and that are sidelined with the focus on goods such as justification and rational persuasion. In my view, even though Cohen's move is a significant move towards a pluralistic account of argumentative goods, his account is still not truly pluralistic in the sense defined above. In his list, Cohen mentions mainly goods that are self-regarding. Even goods that have an other-directed aspect (such as acknowledging the reasonableness of another's position) are not essentially other-regarding. One may aim at acquiring such goods primarily for self-regarding reasons (e.g., to become more knowledgeable oneself). A truly pluralistic list of argumentative goods has to include a number of otherregarding argumentative goods as well. ${ }^{40}$

To be fair, Cohen raises no claim that his list is exhaustive. He only claims that his list is exemplificatory of important cognitive goods that can also be achieved through argumentation, in addition to the more familiar ones. In my view, Cohen's list can be easily expanded to include other-regarding goods. Even though he emphasizes the self-regarding aspects of the goods he mentions, all these goods also have an important other-regarding aspect. As much as argumentation may help arguers to acquire more of the goods on Cohen's list for themselves, it can also help arguers to help other arguers acquire more of those goods for themselves. Through argumentation, for instance, one can also help other arguers to acquire a deeper understanding of their positions; to improve their positions; to abandon their position for a better one; to develop a heightened appreciation of diverging positions; to

\footnotetext{
${ }^{40}$ A full list would also have to include shared goods such as mutual understanding, given that they are also important goods that can be achieved through argumentation.
} 
acknowledge over-looked or under-valued details in their arguments; to acquire a better grasp of underlying connections and of how their arguments might fit together in a big picture. ${ }^{41}$ These are all important goods that can also be achieved through argumentation. And they are all other-regarding. They are all goods whose achievement primarily benefit other arguers rather than oneself (though one may also benefit from this, e.g., by enhancing one's critical insight or creating better partners for interaction). Through argumentation, it is even possible to teach arguers certain virtues, such as intellectual humility (Kidd 2016). ${ }^{42}$

A truly pluralistic account of argumentative goods in the lines just described not only does more justice to the whole range of argumentative goods that is available, but also allows for a richer account of argumentative virtues. It also acknowledges more equally the importance of both self-regarding and other-regarding virtues to the practice of argumentation. As a rule, to foster otherregarding argumentative goods, arguers must exercise a host of other-regarding virtues, in addition to the self-regarding ones.

A truly pluralistic account of argumentative goods also leads to a broader and less agonistic conception of argumentation. ${ }^{43}$ It leads, in particular, to a conception that emphasizes its interpersonal and interactive aspects, especially its cooperative nature. Even though it does not deny that adversariality is a central feature in many argumentative interactions, it stresses that this is not the only way in which argumentative interactions can be conducted and structured. It takes the adversariality that can be observed in

\footnotetext{
41 Socrates is a prime example of an arguer who uses argumentation to help other arguers (his interlocutors in the Platonic dialogues) to achieve more of these goods for themselves.

42 Education in critical thinking, for instance, is by-and-large pursued by argumentation. As several authors have claimed (e.g., Siegel 1988, Paul 1990, Ennis 1996, Facione 2000, Baitlin and Battersby 2016), it is by active participation in practices of critical discussion that arguers come to learn not only the relevant skills-e.g., identifying the structure of arguments, constructing arguments, recognizing fallacies - but also the relevant virtues - e.g., to evaluate opposing views in a fair and open-minded manner, to become aware of the weaknesses of their own views (humility), to be more attentive to detail and so on.

${ }^{43}$ I would like to thank one of the anonymous reviewers for pushing me to clarify this point.
} 
various argumentative interactions as an accidental, rather than a necessary, feature of such interactions, and one that could be smoothed by and on occasion even replaced by more cooperative forms of interaction of the type recommended by other-regarding virtues (e.g., offering constructive criticism to other arguers, helping them identify missed opportunities in their arguments, and so on). It thereby encourages arguers to view each other more as partners in interaction than as opponents involved in a battle to win. Depending on the conception one endorses, a different account of what makes a good arguer would ensue, as well as an account of the relevant virtues. If one views argumentation in pluralistic terms, a more comprehensive conception recommends itself, such as one that views argumentation as a social practice comprised of a set of more specific practices involving argumentexchange and production, joint inquiry and collaboration, critical discussion, and so on, each with its own set of relevant virtues. Some of these practices are more adversarial, whereas others are more cooperative. ${ }^{44}$ This paper, of course, is not the right place to fully articulate such a conception. But, in my view, this conception would be better placed to capture not only the plurality of goods that can be pursued by argumentation, but also the greater importance of both self-regarding and other-regarding virtues than more monolithic conceptions.

The second step that should be taken, in my view, is a more explicit acknowledgment of the variety of roles arguers can occupy in argumentative situations. Whereas some roles require a stronger focus on self-regarding virtues, other roles require a

\footnotetext{
44 Even though this conception makes room for both types of interaction, it stresses that the best argumentative communities are not those in which arguers constantly compete with each other or trade advantage for advantage, i.e. where each arguer serves the good of other arguers only because and insofar as it is to his or her good to do so (i.e., purely for self-regarding reasons). They are communities where arguers care for the well-being of other arguers-and therefore for each other's well-being - for its own sake, and thus make the good of other arguers part of their own good (e.g., Macintyre 1999, p. 108 ff.). In this conception, there is a close connection between flourishing argumentative communities and argumentative friendship.
} 
stronger focus on other-regarding ones. ${ }^{45}$ Examples of roles that are strongly other-regarding are that of a teacher, an interlocutor, a thesis supervisor, a therapist, a commentator. Arguers occupying these roles are primarily in the business of helping other arguers grow as arguers, acting for their own benefit. To be excellently performed, these roles require the exercise of a host of otherregarding virtues, in addition to the self-regarding ones. ${ }^{46}$ Arguers occupying such roles must display, for instance, a good faith disposition to understand the argument being proposed by other arguers with open-mindedness, patience, charity, care, as well as a capacity to hear arguments that are only incipient and not well expressed without being tempted to crush or ignore them. They must also display a willingness to help other arguers improve their arguments by, for example, volunteering friendly amendments to them, asking pertinent questions, giving constructive criticism (helpfulness, gentleness), and so on. Other roles that arguers occupy pose a much weaker focus on other-regarding virtues. As argued before, arguers in the role of proponents, because they are largely in the business of achieving a self-regarding aim (building good arguments in a justificatory sense), must display an array of self-regarding virtues (e.g. determination, self-confidence, perseverance); though, as I claimed before, some other-regarding virtues may be of help here as well (e.g., intellectual charity, attentive listening to the criticism raised by fellow arguers, and so on).

A heightened attention to the variety of roles that arguers can occupy in argumentative situations-especially to the different self-regarding and other-regarding roles - helps to clarify the role that other-regarding virtues have in the context of virtuous argumentation. To expand this point, it would be necessary to embark on a detailed analysis of specific argumentative roles and of the virtues that are required for excellence in each role, which would fall beyond the scope of this paper. Whereas some other-regarding roles that arguers can occupy were already the object of a virtue-

${ }^{45}$ Some virtues seem to apply in general. Perceptual acuity, intellectual diligence, the ability to recognize and assess evidence and to reason well are examples.

46 Though self-regarding virtues, such as intellectual caution and attention to detail, can also be of great help here. 
theoretic analysis, such as that of a therapist (e.g., Cohen and Cohen 1998), other roles were not.

\section{Conclusion}

Despite the progress that has been made in recent years, virtue argumentation theory still lacks a more systematic acknowledgment of other-regarding virtues. Even though the lack of attention to such virtues may be just a circumstantial omission in the field (due to the fact of its novelty), there are also other, more important reasons that explain why this is the case, for example, the oftenmade analogy with virtue epistemology to identify argumentative virtues and the centrality of justification as a goal of argumentation. A fuller acknowledgment of other-regarding virtues leads not only to a richer account of argumentative virtues, one that is better placed to acknowledge all the virtues that are relevant in the context of argumentation, but also to a more intuitive and richer conception of the virtuous arguer. It might also help to counterbalance the strong focus on self-regarding virtues in our current culture and to better place virtue argumentation theory to cover a plurality of argumentative situations. In this paper, I have provided only a preliminary step in the direction of a fuller acknowledgment of other-regarding virtues in virtue argumentation theory, by providing reasons in favor of a stronger focus on these virtues and exploring some of its implications. Other steps, no doubt, have to be taken. An analysis of individual other-regarding virtues and of their role in virtuous argumentation as well as a more sustained reflection on how these virtues can be taught and learnt is still to be done. These steps, however, important as they are, will have to wait for another occasion to be accomplished.

In arguing for the importance of thinking about other-regarding argumentative virtues, I have often cast my points in the form of friendly amendments to the works of other authors in the hope of improving their theories rather than as criticisms of where they have gone wrong. I have done this because I have tried both to argue for the importance of these virtues and to exhibit them in practice. The idea that a friendly amendment should count as an available and praiseworthy move in argumentation-especially 
when engaging with the arguments of other arguers - is at odds with much thinking about argumentation, which is pervaded by adversariality and even certain levels of hostility. Attention to other-regarding virtues invites it in.

\section{References}

Aberdein, Andrew. 2010. Virtue in argument. Argumentation 24: 165-179.

Aberdein, Andrew. 2017. Inference and virtue. URL accessed 29 April 2020: https://my.fit.edu/ aberdein/VirtueInference++.pdf. Aberdein, Andrew. 2017a. Commentary on Jose Angel Gascon, Virtuous arguers: Responsible and reliable. URL accessed 30 April 2020:

https://www.academia.edu/35622304/Commentary_on_José_Á ngel_Gascón_Virtuous_arguers_Responsible_and_reliable.

Adams, Robert Merrihew. 2006. $\bar{A}$ theory of virtue. Oxford: Oxford University Press.

Aikin, Scott F. and J. Caleb Clanton. 2010. Developing groupdeliberative virtues. Journal of Applied Philosophy 27(4): 409424.

Annas, Julia. 2011. Intelligent virtue. Oxford: Oxford University Press.

Annas, Julia. 2008. Virtue ethics and the charge of egoism. In Morality and self-interest, ed. Paul Bloomfield, 205-221. Oxford: Oxford University Press.

Audi, Robert. 1997. Moral knowledge and ethical character. Oxford: Oxford University Press.

Baehr, Jason. 2011. The inquiring mind. Oxford: Oxford University Press.

Bailin, Sharon and Mark Battersby. 2016. Reason in the balance. Hackett Publishing.

Bailin, Sharon and Mark Battersby. 2016. Fostering the virtues of inquiry. Topoi 35: 367-374.

Bailin, Sharon and Mark Battersby. 2018. Inquiry: A new paradigm for critical thinking. Ontario: Windsor Studies in Argumentation. 
Battaly, Heather. 2010. Attacking character: ad hominem argument and virtue epistemology. Informal Logic 39(4): 361-390.

Bermejo-Luque, Lilian. 2011. Giving Reasons. New York: Springer.

Blum, Lawrence. 1980. Friendship, altruism and morality. London: Routledge.

Bowell, Tracy and Justine Kingsbury. 2013. Critical thinking and the argumentational and epistemic virtues. In OSSA Conference Archive 30, eds. D. Mohammed, M. Lewinski, 1-8, Windsor: OSSA.

Bowell, Tracy and Justine Kingsbury. 2013a. Virtue and argument: taking character into account. Informal Logic 33(1): 2232.

Code, Lorraine. 1987. Epistemic responsibility. Hanover: University of New England Press for Brown University Press.

Cohen, Daniel H. 2005. Arguments that back-fire. In OSSA Conference Archive 8: 58-65.

Cohen, Daniel H. 2007. Virtue epistemology and argumentation theory. In Dissensus and the search for common ground, eds. H.V. Hansen, 1-9, Windsor, ON: OSSA.

Cohen, Daniel H. 2008. Now that was a good argument! On the virtues of arguments and the virtues of arguers. In Proceedings of the International Conference on Logic, Argumentation, and Critical Thinking 1-16, Santiago Chile.

Cohen, Daniel H. 2009. Keeping an open-mind and having a sense of proportion as virtues in argumentation. Cogency 1(2): 49-64.

Cohen, Daniel H. 2013. Skepticism and argumentative virtues. Cogency 5(1): 9-31.

Cohen, Daniel H. 2016. The virtuous troll: argumentative virtues in the age of (technologically enhanced) argumentative pluralism. Philosophy and Technology: 1-11.

Cohen, Elliot D., and Gale Spieler Cohen. 1998. The virtuous therapist. Wadsworth, Brooks/Cole.

Drehe, Iovan. 2016. Argumentational virtues and incontinent arguers. Topoi 35: 385-394.

Driver, Julia. 2003. The conflation of moral and epistemic virtue. Metaphilosophy 34(3): 367-383. 
Ennis, Robert H. Critical thinking dispositions: their nature and assessability. Informal Logic 18(2): 165-182.

Facione, Peter A. 2000. The disposition toward critical thinking: its character, measurement, and relationship to critical thinking skill. Informal Logic 20(1): 61-84.

Foot, Philippa. 2003. Virtues and vices. Oxford: Oxford University Press.

Gascon, Jose Angel. 2018. Virtuous arguers: responsible and reliable. Argumentation 32: 155-173.

Gascon, Jose Angel. 2015. Arguing as a virtuous arguer would argue. Informal Logic 35(4): 467-487.

Gilbert, Michael A. 1997. Coalescent argumentation. Mahwah: Lawrence Erlbaum Associates.

Govier, Trudy. 1999. The philosophy of argument. Newport: Vale Press.

Govier, Trudy. 2013. A practical study of argument. Boston: Wadsworth.

Hursthouse, Rosalind. Virtue ethics. In The Stanford Encyclopedia of Philosophy (winter 2016), ed. Edward N. Zalta. URL accessed 19 March 2020: https://plato.stanford.edu/entries/ethicsvirtue/.

Johnson, Christopher M. 2009. Reconsidering the ad hominem. Philosophy 84: 251-266.

Johnson, Ralph. 2000. Manifest rationality. London: Lawrence Erlbaum.

Johnson, Ralph H., and Anthony J. Blair. 2006. Logical SelfDefense. Ontario: IDEA.

Kawall, Jason. 2002. Other-regarding epistemic virtues. Ratio 15(3): 257-275.

Kidd, Ian James. 2016. Intellectual humility, confidence, and argumentation. Topoi 35: 395-402.

Kraut, Richard. Altruism. In The Stanford Encyclopedia of Philosophy (summer 2016), ed. Edward N. Zalta. URL accessed 19 March 2020: https://plato.stanford.edu/entries/altruism/.

Kuhn, Deanna. 2005. Education for thinking. Harvard: Harvard University Press.

Lakoff, George and Mark Johnson. 1980. Metaphors we live by. Chicago: University of Chicago Press. 
Macintyre, Alasdair. 1999. Dependent rational animals. London: Duckworth.

Mercier, Hugo and Dan Sperber. 2017. The enigma of reason. Harvard: Harvard University Press.

Moulton, Janice. 1983. A paradigm of philosophy: the adversary method. In Discovering Reality, eds. S. Harding and M. B. Hintikka, 149-160. Dordrecht: Springer.

Norlock, Karthyn. 2014. Receptivity as a virtue of (practitioners of) argumentation. In OSSA Conference Archive, Virtues of Argumentation, eds. D. Mohammed and M Lewinski, 1-7, Windsor, ON: OSSA.

Nussbaum, Martha. 1996. The therapy of desire. Princeton: Princeton University Press.

Paul, Richard. 1993. Critical thinking: What every person needs to survive in a rapidly changing world. Dillon Beach: Foundation for Critical Thinking.

Pouivet, Roger. 2010. Moral and epistemic virtues: a thomistic and analytical perspective. Forum Philosophicum 15: 1-15.

Roberts, Roberts C. and W. Jay Wood. 2007. Intellectual virtues. Oxford: Oxford University Press.

Rooney, Phyllis. 2012. When philosophical argumentation impedes social and political progress. Journal of Social Philosophy 43(3): 317-333.

Rooney, Phyllis. 2010. Philosophy, adversarial argumentation, and embattled reason. Informal Logic 30(3): 203-234.

Siegel, Harvey. 1988. Educating reason. New York: Routledge.

Slote, Michael. 1995. From morality to virtue. Oxford: Oxford University Press.

Slote, Michael. 2001. Morals from motives. Oxford: Oxford University Press.

Slote, Michael. 2014. Self-regarding and other-regarding virtues. In Virtue ethics and moral education, eds. David Carr and Jan Steutel, 99-110. London: Routledge.

Stevens, Katharina. 2016. The virtuous arguer: one person, four roles. Topoi 35: 375-383.

Taylor, Charles. 2015. Human agency and language, vol. 1. Cambridge: Cambridge University Press. 
Taylor, Gabriele and Sybil Wolfram. 1968. The self-regarding and other-regarding virtues. The Philosophical Quarterly 18(72): 238-248.

Tannen, Deborah. 1998. The argument culture. New York: The Random House Publishing Group.

Thorson, Juli K. 2016. Thick, thin, and becoming a virtuous arguer. Topoi 35: 359-366.

Tishman Shari, Jay, Eileen, and David N. Perkins. 1993. Teaching thinking dispositions: from transmission to enculturation. Theory into Practice 32: 147-153.

Toulmin, Stephen E. 2002. The uses of argument. Cambridge: Cambridge University Press.

Van Eemeren, Frans and Robert Grootendorst. 1984. Speech acts in argumentative discussions. Dordrecht: Foris Publications.

Vlastos, Gregory. 1991. Socrates, ironist and moral philosopher. Cornell: Cornell University Press.

Von Wright, Georg Henrik. 1985. The varieties of goodness. London: Routledge \& Kegan Paul.

Walton, Douglas, Krabbe, Erik C. W. 1985. Commitment in dialogue: Basic concepts of interpersonal reasoning. New York: State University of New York Press.

Waring, Duff R. 2016. The healing virtues. Oxford: Oxford University Press.

Zagzebski, Linda Trinkhaus. 1996. Virtues of the mind. Cambridge: Cambridge University Press.

Zagzebski, Linda Trinkhaus. 2017. Exemplarist moral theory. Oxford: Oxford University Press. 